\begin{tabular}{|lccccc|}
\hline $\begin{array}{l}\text { Social Work/Maatskaplike } \\
\text { http://socialwork.journals.ac.za/pub }\end{array}$ & Werk & $\begin{array}{c}\text { Vol } 51 \text { No 1; Issue } \\
\text { doi:http://dx.doi.org/51-1-429 }\end{array}$ & 5 \\
\hline
\end{tabular}

INTERVENTION STRATEGIES USED TO ADDRESS ALCOHOL ABUSE IN THE NORTH WEST PROVINCE, SOUTH AFRICA

Dr Marilyn Setlalentoa, School of Social Sciences, North-West University, Mafikeng Campus; Prof Elma Ryke, Prof Herman Strydom, School of Psychosocial Behavioural Sciences (Social Work) Potchefstroom Campus, South Africa.

\title{
Abstract
}

One of the purposes of the Alcohol Sub-Study of the Prospective Urban and Rural Epidemiological (PURE) study was to identify the socio-economic effects of binge drinking from the perspective of community support networks and assess their intervention efforts to address the alcohol abuse problem in the selected areas of study. Emphasis was placed on implementation of plans and legislation; however, eradication of the problem seems to be insignificant for various reasons. This article reports on these identified challenges and proposes appropriate intervention strategies that take cognisance of the nature of the communities for which intervention efforts are intended. 



\section{INTERVENTION STRATEGIES USED TO ADDRESS ALCOHOL ABUSE IN THE NORTH WEST PROVINCE, SOUTH AFRICA}

\section{Marilyn Setlalentoa, Elma Ryke, Herman Strydom}

\section{INTRODUCTION AND PROBLEM STATEMENT}

Alcohol abuse has been reported as a major concern and is a source of social and economic problems in many developing countries such as South Africa (Monteiro, 2001:98; WHO, 2014:1). The Minister of Social Development (South Africa), Ms B. Dlamini states that "the emotional and psychological impacts on families, the high levels of crime and other social ills have left many communities under siege by the scale of alcohol and drugs" (National Drug Master Plan, 2013-2017:2). Alcohol abuse places a burden on the social, economic and health wellbeing of drinkers as well as their social support networks. WHO (2008:1) support this statement that harmful drinking leads to negative health and social consequences for the user, the people around the user and society at large. These negative effects of alcohol abuse have to be reduced or eliminated.

Community support networks or service providers such as social workers and police officers and/or the police service have the responsibility to intervene to reduce alcohol abuse and the problems associated with it in partnership with community members. One of the outcomes of the NDMP (2013-2017) is the "ability of all people in South Africa to deal with problems related to substance abuse within communities". This is an indication that intervention requires the services of providers and the community in general. They provide services in communities with an intention to bring different skills, knowledge and experience to combat the problem of alcohol abuse and are referred to as community support networks. Maguire (1983:1) refers to "community support network as those that provide support or services within a particular community for helping residents to meet social-emotional needs, as well as general welfare." For the purpose of this paper, community support networks, service providers or formal support networks will be used interchangeably.

Community support networks provide services to help communities to meet their own social, economic and emotional needs for their wellbeing. They provide resources within any given community that can be potentially tapped by individuals in meeting their needs. It could be an alcohol rehabilitation centre or an organisation that provides services to a community. The community or formal support networks use different approaches or strategies that are aligned in different policies and programme to address the problem of alcohol abuse. Their focus is on reducing the harm that is caused by alcohol abuse by pointing the way to precise targeting of services (Robson \& Marlatt, 2006:255).

In the North West province efforts have been implemented by different community support networks to address alcohol abuse. The critical question is whether there are positive results, and if not, what could be the problem or problems. The Africa Unit for 
Transdisciplinary Health Research (AUTHeR) based at the North-West University Potchefstroom Campus embarked on a cohort study, the Prospective Urban and Rural Epidemiological (PURE) study, which tracks changing lifestyles, risk factors and chronic diseases over a period of twelve years using periodic standardised data collection in urban and rural areas of many countries in transition, including South Africa. One of the sub-studies of PURE, the Alcohol sub-study focuses on understanding the alcohol consumption patterns and the socio-economic effects on support networks. The main aim of the PURE study is to contribute to the development of an integrated, comprehensive and relevant intervention strategy. It is for this reason that this study was pursued, namely to assess the efforts made by community support networks to address the alcohol abuse problem with an aim of contribute to the development of a strategy to address it.

Two areas were selected, namely Ikageng township in Potchefstroom and Ganyesa and Tlakgameng Villages, North West province. The selected communities present with a low socio-economic position and are ravaged by alcohol abuse, binge drinking in particular. Many people are poor, unemployed and depend on social grants and pensions, yet alcohol abuse is high. This is consistent with the views of Zawaira (2009:4) that poverty is one of the problems experienced by people who abuse alcohol in Africa.

According to Lynch and Kaplan (2000:20), levels of education and income are important markers of socio-economic position. Income in particular is a useful measure, because it relates directly to the material conditions that may influence wellbeing. Parry and Bennets (1998:7) are of the view that the prevalence of alcohol misuse is high among residents of disadvantaged communities, where there is easy access to alcohol. Morojele, Parry and Brooks (2009:2) also state that structural factors such as poverty and unemployment make substance abuse problems devastating and difficult to solve in poorer and marginalised communities. Of concern are the negative socio-economic effects that are experienced by the drinkers, families and society (WHO, 2004:60).

Service providers such as social workers, police officers and educators as community support networks are addressing the socio-economic problems, amongst them, alcohol abuse. Rataemane (2004:13) mentions some of the interventions used such as providing information on alcohol, positive engagements with youths in and out of school, promotion of responsible use, treatment and rehabilitation. However, the outcomes are still negative and implementation seems to be a challenge.

The government of South Africa has introduced legislation to deal with the problem of alcohol abuse to reduce its harm, demand and supply such as NDMP (2013-2017), the Prevention and Treatment of Drug Dependency Act (20 of 1992), as amended, as well as the Prevention of and Treatment for Substance Abuse Act (70 of 2008). Rataemane and Rataemane (2006:373) refer to alcohol harm reduction focusing on reduction of problems stemming from alcohol abuse, such as violence, road accidents, loss of productivity and spread of sexually transmitted diseases resulting from unsafe sex. The community support networks are responsible for implementing these policies, programmes and plans to address alcohol abuse. The challenge is that the problem 
persists irrespective of the efforts by government, non-governmental organisations and the industry. The harm that is caused by alcohol abuse has far-reaching negative effects that affect the drinker as well as those who are part of his immediate environment and the society as a whole, including those who provide services that are meant to reduce or eradicate the problem.

This article seeks to:

- Report on strategies that are employed by community support networks to address the problem of alcohol abuse and reduce the harm it causes;

- Propose intervention strategies that could be used to address the problem of alcohol abuse.

\section{RESEARCH METHODOLOGY}

A qualitative approach was adopted to obtain the views of key informants. Unstructured face-to-face interviews and focus group interviews were conducted using open-ended questions to obtain as much information as possible pertaining to alcohol use amongst communities they serve and strategies used to address the alcohol problem. A purposive sampling strategy was used. The identified key informants were direct service providers involved in events and activities pertaining to alcohol harm reduction in the selected communities of study. These key informants were from the Department of Social Development as workplace service providers and responsible for substance abuse programmes, the South African Police Service and two high schools. Content analysis was used to analyse qualitative responses to open-ended questions in interviews and focus groups. Data were considered from different angles with a view to identifying keys in the text that helped to understand the efforts and experiences of the participants and intervention strategies employed to combat the alcohol abuse problems.

Documents in the form of legislation and national plans were studied to provide a base to analyse intervention strategies that are developed and implemented. Flowing from this analysis and benchmarking, intervention strategies are proposed. The analysis of information provided led to the formulation of recommendations on reducing abuse and harm that is caused by alcohol abuse. The proposed intervention strategies are outlined focusing on the themes such as assessment of risk and risk environment, targeted interventions, multi-level synergistic intervention and multi-sectoral responsibility and partnerships as proposed by Stimson (2006:9).

\section{Ethical consideration}

Permission to conduct the study was granted by the North-West University Ethics Committee, the North West Departments of Social Development, Education, and Police Services.

\section{RESULTS}

The identified themes focused on current intervention strategies employed by community support networks and suggestions for intervention are proposed. The key informants were of the opinion that alcohol abuse has detrimental effects on the 
workplace, individuals, families and the community. It affects the quality of life and exposes the social support networks to abuse, neglect, hunger, premature death, poverty and injury, to mention just a few consequences.

\section{Social workers}

Social workers confirmed that there is a high rate of alcohol abuse, especially binge drinking, in both selected areas. It occurs during the week but more during the weekends using homebrewed alcohol. Beer and ciders are consumed, but not much because they are expensive. One social worker noted:

"We have noticed a high number of children who are neglected because their parents abuse alcohol and spend most of the time away from home. They are always visiting shebeens. The patrons of the drinking venues are exposed to fighting, injuries and at times death due to alcohol abuse. The frequent patrons of shebeens are men, women and young people and this is a cause for concern. Many people are not employed; they depend on pensions and casual jobs, but opt to use the money for alcohol. People indulge in binge drinking on paydays and they do so excessively."

The social workers reported that there are many drinking venues (shebeens and taverns) in the community that contribute to the social problems of these communities. Parents spend most of the time away from home, leaving young children without proper care and support. The neglect and abuse of children are part of the costs of excessive alcohol consumption, because it leads to emotional, physical and educational problems (Zawaira, 2009:10). There is a need to improve the situation because in some families, both parents abuse alcohol. Family disruption is rife and has led to other related problems such as juvenile delinquency, teenage pregnancy, and HIV and AIDS. Parents are not good role models. The key informants reported that youths as young as 18 years of age are at risk because they abuse alcohol. They leave school before Grade 10 to do seasonal work on farms. On their return, they drink excessively until the money is finished. One social worker said the following:

"It is a practice that the young ones go to farms for seasonal work. They would leave school or a job when the time comes to go to the farms. The learners would leave school to make money in this kind of employment. The money they receive is spent on alcohol."

For the youths in particular, the situation in the selected areas is similar to what Meel (2006:1) found when she conducted a study in the Transkei that highlighted that binge drinking among youths, especially males, is high.

The social workers reported that there have been people who needed rehabilitation in an alcohol treatment centre. In a period of eighteen months prior to the interview, the social workers at Ganyesa referred five people to a rehabilitation centre that offers in-patient services. However, this has not been very successful, because all five relapsed, some left treatment before completion and they were not motivated to stop drinking. The social workers further stated that they are also not able to form after-care groups, because the 
patients come from scattered communities and have no resources to meet at one point. After-care is also a challenge because the clients do not participate; for example, group work is not practised even though it could be effective in addressing the problem.

The social worker who is responsible for probation services stated that many crimes committed by young people are alcohol related. The crimes that have been recorded in both areas of study include murder, rape and assault with grievous bodily harm. For young people substance abuse is often associated with serious and often devastating social problems such as crime and violence (Parry, 2009:1). One social worker went on to say that incest has also occurred, but the challenge is that the family would engage in victim-offender mediation and avoid laying a charge. In her view, this perpetuates the problem because the perpetrator could continue to abuse children knowing that the family would not lay a charge against him.

One of the challenges is unemployment in both areas. To reduce poverty and unemployment the Expanded Public Works Programme (EPWP) was established (Nzimakwe, 2008:208). The Department of Social Development in particular contributed by employing people through non-governmental, community and faith-based organisations (NGOs, CBOs and FBOs) to work on projects such as home-based care, early childhood development and community development. The job opportunities were open to youths, women, men and disabled people. Skills development training opportunities were created by various other government departments to develop various skills such as bricklaying, carpentry and plumbing. Efforts to involve the participants from the communities of this study in EPWP development projects have not yielded good results, because the community members were not interested.

The social worker explained:

"The community members are not motivated to engage in community projects.

They are not self-reliant but at the same time they want money. They always come to social work offices to demand pensions."

The reasons stated for not participating in projects are that community members want to receive money in a short period and they are not prepared to wait for profits that take longer to be realised. At the same time they are not doing much to find employment, even though some of them do not qualify for pension. The social workers explained that the community members receive pensions and grants, which tends to make them dependent on the state. Many families are beneficiaries of pensions and grants as their only source of income. The beneficiaries use this money for alcohol and very little goes towards maintenance of the family and this aggravates the poverty. The situation is even worse in the area where there is no social worker who is responsible for dealing with substance abuse.

\section{Members of the South African Police}

The police were identified as one of the community support networks who provide public safety and security services. In both areas, Ganyesa and Ikageng, they reported that there are many cases of alcohol-related crimes, especially over the weekends, 
though they could not provide statistics. The problem of alcohol abuse is seen among youths and adults, both women and men. Domestic violence is rife and most of the time it is associated with alcohol. Assaults take place at drinking places and at times the patrons die as a result of fights and injuries sustained. According to Meel (2006:2), in South Africa $76 \%$ of all deaths after interpersonal violence have been shown to be alcohol related. The Women's Rural Advocacy Programme (2007) has indicated that data on the concurrence of domestic violence and alcohol abuse vary widely, from as low as $25 \%$ to as high as $80 \%$ of cases. Alcohol is also associated with high trauma rates on South Africa's roads. A police officer said:

"To show that young people visit shebeens and abuse alcohol: A 20-year-old was stabbed this past weekend at the shebeen and there was a fight. He was stabbed to death by a 21-year-old. He is in the cells at the moment. A young life was lost prematurely. We are experiencing many challenges in this community."

Efforts to fight crime are hindered by challenges such as alcohol and drug abuse that continue to be generators of crime (Nqakula, 2006) and interpersonal violence, which places a huge burden on communities and individuals (WHO, 2005:1). A police officer referred to cases of rape where women were at or from a drinking place.

"Women also frequent drinking places. There have been cases of rape, older and young women are victims because they all drink and try to walk home alone. In some cases men buy alcohol for women with an intention to have sex with them when they are under the influence of alcohol".

The WHO (2008:2) states that young women who visit bars frequently are at greatest risk of being victims of sexual aggression in nightlife environments, whereas men are more likely to initiate acts of sexual violence. The impact of sexual violence on both physical and psychological health can be devastating, long lasting and even fatal. The latter could be due to HIV and AIDS infection, which could lead to death and the support network experiences loss of a loved one or a breadwinner.

One of the main challenges is to cope with many shebeens in the communities. They are risk environments that are a danger to communities, but they also put a strain on police services because the unpleasant deeds are unpredictable, as is evident from this statement by a police officer:

"The problem is that there are many shebeens in the community that sell homebrewed beer and other intoxicating beverages. The police officers often raid them but they continue to sell. The situation is worse during weekends."

It has been noticed that most of the drinking is done at shebeens, where dangerous concoctions are brewed and sold to the public, and cause social and health problems. Alcohol consumption at the shebeens very often leads to violence, assaults, stabbings, rapes and murder, to mention a few. The police officer also reported that many of alcohol-related problems are experienced mostly during the weekends, at homes and shebeens. This is consistent with the study conducted in Russia by Pridemore 
(2006:1034), which has shown that there is a link between alcohol consumption and violence as a result of the high rate of binge drinking on weekends.

\section{School educators}

The school as a community support network is also experiencing a problem of alcohol abuse by learners. It was reported that this maladaptive behaviour makes teaching and learning very difficult. The culture of learning is affected by an unresponsive environment, where the majority of the population is uneducated and unemployed. The use of alcohol is a major problem even on school premises. A teacher observed:

"Alcohol abuse is a real problem in schools. The learners stay away from school because they drink alcohol during weekends. They leave school during the day to drink alcohol. Even though parents are poor, government has no-fee school, therefore, they are provided with an opportunity to learn."

Many parents are not helpful because they also abuse alcohol and most of them are not literate. The parents do not participate in facilitating learning or other activities related to schools.

"We are struggling because parents abuse alcohol as well. A teacher cannot also get support from home because parents are not literate and some still do not understand their role in helping children with learning".

The teacher also expressed the point that learners leave school before they reach matriculation to work on the farms.

\section{CURRENT INTERVENTION STRATEGIES THAT ADDRESS THE PROBLEM OF ALCOHOL ABUSE}

There were 12 social workers operating at Ikageng township and not one of them was dedicated to dealing with alcohol abuse programmes. The one interviewed stated that she was involved at some stage but not anymore, and there is no one who is responsible for the substance abuse programme. The cases are dealt with as and when they are reported. There are 18 social workers operating at Ganyesa and Tlakgameng villages and one is specifically responsible for the substance abuse programme. She is involved in prevention, protection, promotion and rehabilitation services. The South African Police could not provide the number of members operating at the local police stations. There are six high schools at Ikageng and two at Ganyesa and two at Tlakgameng villages. Social workers and other stakeholders participate in varying degrees in implementing the National Drug Master Plan. Intervention programmes that are implemented in both areas are Teenagers Against Drug Abuse (TADA), Young Adults Against Drug Abuse (YAADA) and the Local Drug Action Committee is active. The key integrated strategies are focused on reducing supply, demand and harm to users, their families and communities at large.

The social workers are responsible for observing the anti-drug week during Youth month in June. The activities are focused on disseminating information to educate and make people aware of the dangers of substances. The campaign involves a door-to-door 
awareness programme for individuals and families, visits to shebeens and taverns and presentations at schools. Social workers alluded to the fact that many families have one or both parents and children who are abusing alcohol; the drinking venues are always full of people drinking alcohol; and the owners of these places offer alcohol on credit and are not concerned about the young people under the age of 18 years who frequent these places. They are not even aware of the age restrictions.

\section{PROPOSED INTERVENTION STRATEGIES TO ADDRESS THE ALCOHOL ABUSE PROBLEM}

Awareness of alcohol and related socio-economic problems and the need for collective action is needed in communities. However, more emphasis needs to be given to reviewing intervention efforts and policy implementation in an integrated manner. Attention needs to be given to internal and external environments to be able to win the war against alcohol abuse. There is a need for an alcohol-reduction strategy that is relevant and appropriate for the communities. Stimson (2006) is of the view that the reason programmes fail is that they are not contextualised. One type of plan is developed for areas, no matter how different they are.

Strategies are proposed based on Stimson's (2006:9) intervention themes that focus on assessment of risk and risk environment, targeted interventions, multi-level synergistic interventions and multi-sectoral responsibility and partnership.

\section{Assessment of risk and risk environment}

Stimson (2006:9) claims that evidence-based interventions and evidence-informed policy are likely to be more effective in addressing alcohol problems. His argument is that effective interventions should be identified as well as the costs. It is also critical to identify those interventions that are likely to be relevant, feasible and appropriate. There is a need to develop capacity to assess the risk environment, especially at local level.

Alcohol harm reduction strategies should be informed by a proper assessment of the risk and risk environment that is performed by all role players such as social workers, police, health workers, educationists, traditional leaders and policymakers. The risk assessment calls for a change in prevention of alcohol abuse itself to prevention of risk factors. Medina-Mora (2005:26) states that risk factors should be identified at all levels such as individual, family, school, among peers and in the community. Evidence from the environment would provide relevant information that guides in developing a strategy that focuses on interventions that are likely to be effective (Stimson, 2006:9). A proper assessment of the environment, taking into consideration culture, human, financial and infrastructural resources, and socio-economic status of the community is important. It would determine the kind of intervention that is appropriate to reduce harm. In order to reduce the harm caused by alcohol, the individuals, families, community, organisations and government need to accept that the problem exists and are willing to take action to address it.

The key informants reported that there was no study or assessment done to determine the extent of the alcohol problem and risks in their communities. Intervention strategies 
were developed at national level and applied in all areas. It would seem that there is intervention in some areas, but no assessment was done to determine the appropriate intervention suitable for the locality, particularly those who present with the kind of socio-economic situation such as at the two selected areas of study (low level of education, poverty and unemployment). Medina-Mora (2005:26) says contextual factors such as poverty, neighbourhood disorganisation, lack of health and social services, and availability of substances are important determinants of the level of use and problems. Evidence-based interventions are informed and are likely to target the identified risks. Policy should be checked for local transferability and feasibility of implementation.

Poverty, low level of education, unemployment and dependence on pensions are contributory factors to the situation. Efforts to address alcohol abuse are thwarted because problems are multifaceted. According to Stimson (2006:9), a proper assessment of risk and the risk environment should consider effective interventions that are likely to be effective, but of course the cost should also be determined. Budgetary allocations should cater for alcohol programmes. The police and social workers alluded to a shortage of funds that affects service delivery.

Stimson further states that "off-the-shelf solutions" in tackling alcohol issues are not effective, relevant, feasible and appropriate for everyone. The point is emphasised by Parry (1998:130) that interventions should be designed for the particular communities they are meant to reach. Generic programmes may not be effective for tackling the alcohol problem in some areas.

An assessment is meant to provide a holistic ecosystems' view of the community such as their strengths and socio-economic position, amongst others, which could be used to develop intervention strategies, instead of developing a policy that should fit all, irrespective of their shortcomings or resources. Mokdad, Brewer and Warner (2007:304) support this view that evidence-based prevention strategies such as enforcing age restriction and reducing alcohol outlets can help change social norms regarding acceptable drinking behaviour and thereby reduce excessive alcohol consumption and related harms. Research should be done in order to obtain relevant and appropriate information that would assist in planning and intervention. The National Drug Master Plan (2006-2011) was developed for all the provinces in South Africa and no specific interventions were proposed for different areas, irrespective of the fact that the population is diverse and unequal in terms of resources and education, amongst other things. These areas have not developed their Mini-Drug Master Plan as proposed.

For a proper assessment to be done there should be capacity to assess the risk environment, especially at local level. The numbers of professionals in the selected areas of study are inadequate. It would not be possible to do a proper assessment that would assist in designing strategies and helping policy makers to make informed decisions. Capacity to assess the risk environment is needed and one social worker would not be able to do a proper assessment. There is a need to increase the number of social workers and also to consider employment of other categories of social service occupations such 
as social auxiliary workers and community development officers to provide assistance to social workers.

The departments and organisations that are involved in the local drug committees are not experts in the field of alcohol abuse. As much as social workers study specialised fields of practice during their graduate training, it would be advisable to pursue studies specifically on alcohol abuse to gain specialised knowledge and practice for effective interventions.

Capacity is also needed in other structures, such as schools, to be able to assess risk. Teachers reported that they are at times faced with psychosocial challenges which they are not able to address because they are not trained to do so. Employment of social workers in school would provide capacity to assess the risk environment and take appropriate action.

Community members have capacity in prevention as well as early identification and intervention in alcohol abuse-related problems. This intervention would require people with basic education to understand what they are supposed to do. The challenge is the low level of education in the community. However, attention needs to be given to identify community members who are willing to participate and should be assisted to build capacity. Ownership of intervention programmes could assist in treatment and contribute to reducing the harm that is caused by alcohol. This view is supported by Rataemane (2004:7), who claims that "treatment works with the support of family and community"; therefore, empowering the community to mobilise around alcohol and related issues can be a powerful strategy.

The local drug action committees should be involved at all levels of assessment and ensure that their areas of operation also involve people with capacity to assess risk and risk environment. Knowledge about alcohol abuse and intervention strategies is needed to be able to address the problems. The local drug action committee members are identified by their departments and the majority of them are administration officers who act as employee assistance officers. They do not have people who are qualified in the psychosocial fields. For instance, the community support networks, such as the police, have appointed social workers to address the psychosocial needs of police officers, but they are based far from the Ganyesa area. While the situation still prevails, the members of the local drug action committee representing different departments and organisations should be trained to assess risk.

The rationale for doing proper assessment is to facilitate identification, assessment and treatment of alcohol problems. The end result is to come up with intervention strategies that are relevant for the context and not try to apply one generic strategy for the whole country that does not provide for the different environmental conditions. Parry (2000:219) states that a single policy formula is not good; instead a mix of strategies is needed that will work to determine appropriate ones taking into account factors such as capacity to respond, political feasibility in different cultural contexts, public acceptance and likelihood of impact. 


\section{Areas that should be targeted for interventions}

According to Stimson (2006:9), targeted interventions should focus on contexts such as drinking venues, specific groups such as vulnerable young people and the elderly, and behaviours such as extreme drinking, alcohol abuse and unsafe sex. Targeted interventions reported by the key informants included drinking venues, schools and homes.

Intervention was targeted at drinking venues, but it seems that it was done on a once-off basis during the anti-drug week. The police visit the drinking venues randomly, but can only do so if they know about existence of such a venue. They stated that the number of drinking venues in the villages and township is not known because they operate illegally.

Many shebeens in the communities are not registered and, therefore, fail to adhere to the law pertaining to production and selling of alcohol. Many outlets are unlicensed alcohol outlets in South Africa and this weakens the influence of any measure aimed at reducing under-age drinking. The young people are vulnerable because of lack of enforcement of age restriction laws in the bars, supermarkets and alcohol stores.

Efforts to change the situation should be directed at owners of the drinking venues by involving them in education programmes that focus on responsible drinking. They could also be motivated to participate in other income-generating projects rather than use illegal ways of generating income. Enforcement of the laws that monitor licensing needs to be given attention.

There are specific groups that require attention because they are vulnerable, for example, school going children, young people, women and the elderly. Martinic (2006:11) states that those individuals at particular risk of harm can be specifically addressed. The key informants registered concern regarding all these groups.

School-going children should be targeted to prevent them from using alcohol. Prevention is still better than cure. This could include any activity designed to avoid substance abuse and reduce its health and social consequences (Medina-Mora, 2005:25). School children are vulnerable and therefore require prevention programmes such as life skills to protect them from the harm that is caused by alcohol abuse. According to Ebersöhn and Eloff (2006:57), life skills are all kinds of skills and capacities that an individual needs to be able to enrich one's life in a meaningful way. The aim is to develop their core life skills such as problem solving, decision making, creative and critical thinking, and their self-concept (Couch, Felstehausen \& Hallman, 1997:16-32). It was noted that the TADA programme was introduced in one school in Area B, which is a good effort. It would be beneficial to evaluate implementation and impact. This should then be extended to other schools to facilitate these skills.

Therefore schools should consider employing social workers who will be dealing specifically with psychosocial issues affecting school children. The social workers would serve as a link between schools and the homes of the children, and they will at the same time work with families that need assistance in order to create an environment 
conducive to learning and development. The teachers as well would be capacitated by the social worker and other specialists who could be invited to school to share knowledge and skills such as early identification of behavioural problems.

Provision of information on alcohol and its effects on the human body is relevant for young children as a preventive measure. Children are vulnerable because they are neglected by parents who are abusing alcohol. They are exposed to negative psychosocial effects such as delinquency, home accidents, or physical or sexual abuse.

The youths are vulnerable and should be assisted to deal with peer pressure to be able to stay away from alcohol use. Parry (1998:13) also contends that life skills programmes should be designed to address the attitudes of youths towards binge drinking and should also take into account the influence of normative factors and self-identity on the intention of males to engage in binge drinking. Involvement of role models who have recovered from substance use could motivate youths to participate in programmes. The YAADA programme was introduced without success, even though it is an intervention strategy to address the problem faced by youths. An evaluation of the situation that involves youths would help, because they have other needs to address such as unemployment, as expressed by the social worker. A holistic approach could yield better results.

In order to get the youths to participate in the programmes, it is suggested that these programmes should be run by the youths themselves, especially those who are recovering from substance abuse. They could run workshops, seminars and also focus on other issues of interest, such as employment and educational opportunities. Use of role models such as musicians who play their kind of music could assist in changing behaviours. Participation of a youth representative in the LDAC is also recommended.

Parents and families need to be targeted for change, growth and development of the individuals and their families. There is a need for services such as screening and early identification of families who need support and assistance of prevention programmes. Effective parenting skills could be introduced to capacitate parents to deal with parenting difficulties, maintaining a home, setting rules and boundaries, and developing support networks. Parents who abuse alcohol are not good role models, because young people who are exposed to families where alcohol is misused are more likely to model this behaviour or to consider it as acceptable. Focus should be on building healthy families, where good values are instilled to ensure that children grow in a supportive, caring environment. Cultural practices that curbed alcohol abuse in the past could be reintroduced, with the tribal authority leading the process.

A door-to-door campaign was used by committee members, where families to disseminate information on alcohol use and abuse. Much as it is commendable, it was done once during the anti-drug week. Information was provided, but considering the level of education of the majority of community members, it is not possible for them to grasp and do something about the binge drinking problem. Motivating drinkers to stop abusing alcohol cannot be done in one session. 
The high unemployment, poverty and illiteracy rates are contributory factors to alcohol abuse. The social workers as key informants were of the view that participation in community development programmes could ease the problem. There is a need for vigorous drives by structures such as the Department of Labour to facilitate skills development in different trades. Other departments such as Agriculture, Health and Education could focus on other skills and adult education.

The social workers further stated that one shortcoming was a lack of recreational facilities in both areas. Shebeens are used for meeting friends and for entertainment, yet they were established as resistance to apartheid policies (Parry, 2005:426). Freeman (undated) states that poverty and apartheid had an effect on the use of alcohol in that people drank because the government did not supply other recreation facilities. This situation remains a challenge for the present government to provide recreational facilities to keep people away from alcohol.

Community involvement ensures that the community takes control of their lives and becomes self-reliant. The vision of the White Paper for Developmental Social Welfare (1997:14) was to facilitate the development of human capacity and self-reliance within a caring and enabling socio-economic environment. This notion of self-reliance is expressed with caution, considering Hochfeld's (2007:84) view that the discourse of self-reliance is problematic in terms of its expectation of economic self-sufficiency of families in the context of high levels of unemployment and extreme poverty. In this instance, self-reliance is emphasised for change of behaviour in as far as alcohol abuse is concerned. Members of society have to take responsibility to change behaviour and refrain from using poverty as a reason for abusing alcohol, because the damage caused by alcohol is huge and, if not curtailed, damage could lead to death. In some instances it leads to more poverty and becomes a vicious circle.

Parents should be involved in helping young people not to abuse alcohol. An article in the Sunday Times of 19 July 2009 (p. 2) states that the authorities in the Italian city of Milan want parents to take responsibility seeing that "parents of children under the age of 16 years who consume, buy or even possess alcohol will face a fine of $€ 450$ ". The mayor, Letizia Moratti, said this was necessary to protect young people because children as young as 11 years have already experimented with alcohol and one sixth of hospital admissions for alcohol abuse involves youngsters less than 14 years of age. It might not be possible to enforce this kind of intervention in South Africa because of high levels of poverty and unemployment; however, it could serve as a deterrent for those who can afford it. But even though those who cannot afford it could get an option of detention, it might not change the behaviour. Programmes such as effective parenting skills and implementation of legislation to protect children should be monitored.

Focus on moral regeneration could assist in changing the unacceptable behaviours, but for success to be realised a coordinated intervention is needed. Planning and implementation with clear monitoring and evaluation mechanisms are critical. The community needs to take responsibility to address the problem. Use of assets of the wider social system such as community associations and local institutions could be used. 
Ebersöhn and Eloff (2006:25) refer to the theoretical framework for the eco-systemic perspective that would include the whole social system, wider community and local community including families and individuals.

The focus should be on continuous education in all spheres such as families, schools, social clubs, churches and professionals such as social workers, priests, nurses or teachers should take the lead and share knowledge such as recommendations from the WHO. The WHO Africa (2008:4) encourages public education on the negative consequences of drinking alcohol that it can be effective in increasing recognition of alcohol-related harm in the community and providing active participation in policy measures. Education should be extended to community, schools, mass media and social marketing campaigns and passive measures such as warning labels. The challenge is to continue motivating the community to change the mind-set and make themselves selfreliant. There is a need to increase community action and support.

Community development encourages people to take control of their development and this can be a solution in terms of dissemination of information, training and education. Identification and involvement of community leaders, experts and role models would add value to efforts to address the alcohol problem. Mkhize (2006:4) states that the alcohol harm-reduction strategy needs ambassadors, champions and role models. The structures such as government departments, civil society, business and tribal authority could identify people in their respective areas to facilitate change.

Behaviour change should be encouraged and maladaptive behaviours such as heavy episodic drinking at parties, customary events and weddings should be discouraged. Zawaira (2009:7) identified risk factors such as weak cultural controls as contributing to alcohol abuse. Cultural teachings could be re-introduced to change behaviours. Interventions should be targeted to change behaviours by using life skills, enforcement of laws, spot checks at schools and general education on responsible drinking. The social workers should assist clients to unlearn maladaptive behaviour. Therefore, behaviour modification as an intervention approach could be used to change maladaptive behaviour and also change the environment to make it responsive to peoples' needs. McLeod, (2010) is of the view that behaviour is learned and can therefore be unlearned. It means then that alcohol use is learned and therefore can be unlearned. The social environment influences behaviour by shaping norms, enforcing patterns of social control and providing or not providing environmental opportunities (Berkman \& Kawachi, 2000:7). Incorporating the social context in behavioural interventions would include communities, different helping professions and work places to achieve behavioural change.

\section{Multi-level synergistic interventions}

According to Stimson (2006:9), multi-level synergistic interventions separating drinking from risky activities should be developed at various levels. 


\section{Enforcement of laws aimed at alcohol abuse reduction}

There are laws such the Liquor Act (Act No 59 of 2003) and National Drug Master Plan in South Africa that focus on alcohol use, covering aspects such as the production, distribution and consumption of alcohol. The information from the key informants indicated that enforcement of this law is weak. Because home-brew beverages are unrecorded, production is not controlled and they are sold in unregistered outlets, it becomes very difficult to control their consumption. The unregistered outlets also sell beer and distilled drinks. According to WHO Africa (2008:2), alcohol use in African countries includes home-brewed and industrial beverages, thus increasing the total amount of alcohol intake. This consumption poses challenges regarding quantities consumed and safety issues related to the unregulated production of alcohol.

However, dealing with the challenge requires a concerted effort from all role players. The synergy between all role players would certainly reduce the harm caused by alcohol if all are focusing on addressing the problem. It would require better coordination and enforcement of the laws. Teamwork is one way of ensuring that all coordinate their efforts.

Enforcement of the Liquor Act No 59 of 2003 requires more police who are well resourced, if they are to manage the problem. It would require those who sell alcohol to be involved in information dissemination and programmes that educate people on the dangers of alcohol. They should not be concerned with commercial gain at the expense of the wellbeing of people, but rather be involved in helping them to control their alcohol use. Restrictions on selling alcohol to under-age people needs to be enforced, even if it means investing more money for better control and enforcement systems. In order to regulate the availability of alcohol, some controls are needed. WHO Africa (2008:5) states that control has shown to be an effective strategy in a variety of sociocultural circumstances.

One example of stricter control is found in the Western Cape province, which has developed a law to address alcohol abuse. The Western Cape Liquor Act (Act No 4 of 2008) was introduced in an effort to exert greater control over the liquor industry. The aim is to enforce stricter criteria for successful licences, reduce the number of available liquor outlets by prohibiting shebeens from operating in residential areas, and control of trading hours. It is reported that there are 3200 legal sellers and about 30000 illegal outlets in the Western Cape, and it is estimated that implementation of the aforementioned Act could result in between 60000 and 100000 jobs losses. It was reported in the Mail and Guardian online (27 January 2009) that the Provincial Minister of Finance, Economic Development and Tourism expressed his concern about the effect that these illegal outlets has on communities, especially those who live in close proximity to liquor outlets associated with crime and gangsterism. The members of communities support the Act, because of the negative effect the outlets have on them.

It is acknowledged that these recommendations would lead to loss of income for those who sell alcohol from their homes; however, the shebeens have long-term social implications for the safety and wellbeing of communities. Because of the probable loss 
of income, there were about 600 shebeen owners and workers who marched to the Western Cape legislature in protest against new legislation that was passed in November 2008. However, the Western Cape government is more concerned about the harm than the money lost. It is critical that community information, mobilisation and support mechanisms for alternative means to generate income are put in place to assist those who are in need.

The Prevention of and Treatment for Substance Abuse Act (Act No 70 of 2008) was developed to deal with the prevention of and treatment for substance abuse such as alcohol and the associated harm, the rehabilitation of service users in the various institutions and the reintegration of service users in their communities. The prevention programmes need to be on-going and not once-off, and treatment should be more intensive and in order for this to happen, more people (professional and auxiliary workers) are needed. There is a need for rehabilitation centres specifically addressing substance abuse problems. However, hospitals could establish a ward for admission for alcohol abuse patients and a multidisciplinary team could then give proper attention to patients to reduce harm to individuals. There is a need for employment of more social workers who should deal specifically with substance abuse programmes.

The aforementioned Act, Chapter 2, p. 14 states that organs of state must adopt a multifaceted and integrated approach to enhance coordination and cooperation in the management of substance abuse and ensure the effective implementation of the National Drug Master Plan.

There is a need to include more social workers in the field who would liaise with families and community structures that could assist with aftercare services. Provision of after-care services has been emphasised in the Prevention of and Treatment of Substance Act No 70 of 2008. The services are meant to provide on-going professional support after a formal treatment episode to maintain sobriety, abstinence and personal growth, and to enhance self-reliance and proper social functioning. The partners such as social workers and health practitioners could consider using the local hospital for admission and more field workers are needed to monitor progress. There is a need to train community care workers, who would work with the social workers because there is a shortage of social workers in the country.

\section{Changing of drinking culture of communities}

The key informants were concerned about the culture of drinking and drinking environments in the two areas. It is very difficult to change culture especially when it has gotten out of hand and there is very little understanding by the people who abuse alcohol. However, shebeen owners need to be included in efforts to teach people about the dangers of alcohol abuse. Education should be extended to all areas, including the drinking environments. For example, the Liquor Boards could go on road shows to educate people about the Liquor Act (Act No 59 of 2003) and emphasise the importance of, for instance, licensing and production of alcohol. Enforcement should be preceded by education. Stimson (2006:9) refers to responsible hosts that would extend their role to ensuring that patrons are assisted to be responsible drinkers. Changing drinking norms 
from bad to good ones could reduce the harm caused by alcohol abuse. Shifting from a national to a community approach to devising strategy (from one size fits all to a community-specific solution) would also be beneficial.

\section{Helping individuals to take responsibility for positive change}

Individuals remain responsible for their rehabilitation, if positive changes are to be realised. Robson and Marlat (2006:257) state that harm reduction can include working with individual drinkers, helping them to manage their problems with more insight. Awareness programmes such as information dissemination are methods of intervention that capacitate people to make informed choices. Learning life skills as a preventive measure could help children from an early age to be aware of dangers of alcohol, make the right choices and take responsibility for their lives. Drinking responsibly should be emphasised for individuals to take control of their lives. Heavy episodic drinking in particular is dangerous and individuals need to be aware of its negative effects.

\section{A multidisciplinary approach to address the alcohol problem}

Stimson (2006:9) states that multi-sectoral responsibility and partnerships are essential to manage the problem of alcohol abuse. Community support networks have different roles and responsibilities to perform which would ensure that alcohol harm is reduced. There is a need for a balanced approach that focuses on all aspects pertaining to addressing alcohol and related problems - for instance, enforcement of opening and closing times of alcohol outlets, ensuring that health standards are met, making sure that streets have sufficient light and that social order is maintained, to mention a few. These could facilitate alcohol harm reduction or elimination. This would require involvement of all stakeholders to execute their roles and responsibilities and can be realised if all coordinate their efforts to address the problem. Performance of roles as individual entities and as a collective is crucial in addressing socio-economic and behavioural problems. Different roles bring particular skills, knowledge and experience that could yield good results. The positive changes are possible if strong partnerships are formed, with clear mandates, responsibilities and focus on alcohol harm-reduction strategies. The National Drug Master Plan (2006-2011) calls for shared responsibility and strong partnerships to address the problem, which will certainly reduce the harm to individuals and others in their social environment. Partnerships should be established to share costs, but most importantly, to address the problem focusing on all aspects.

The plan outlined strategies for prevention, early intervention, treatment, after-care and reintegration. In addition, the policies also include community-based intervention, capacity building, management of treatment practices and information management. This comprehensive action plan is meant to facilitate contributions and clarify responsibilities of the various sectors, partners and stakeholders. Much as the teams in Ganyesa and Ikageng are trying to implement the National Drug Master Plan and the Prevention of and Treatment of Substance abuse of 2008, there are still many challenges. Gaps in the implementation and monitoring of these policies and programmes have been evident. There is a need for coherent, consistent and strong action with relevant actors for the plan to succeed. The then Minister of Social Development, in a media statement 
in May 2008, stated that the Department of Social Development is the leader in reducing the abuse of legal and illegal drugs; however, other government departments and nongovernmental organisations need to be involved to ensure that they mitigate the impact of the problem through the provision of prevention and treatment services.

For intervention to succeed there should be financial, human and infrastructure resources for proper implementation. Social workers identified office and staff as some of the challenges to be addressed. This situation was also highlighted by Zawaira (2009:13) that there are low budgetary allocations for addressing alcohol-related problems in Africa. This results in failure to implement policies aimed at addressing the problem.

\section{DISCUSSION AND CONCLUSION}

For effective intervention strategies to curb the alcohol abuse problem in the selected areas, community support networks need to recognise that they are not dealing with alcohol abuse only, but problems such as poverty, unemployment and inadequate education/skills development because socio-economic problems are multifaceted. It is also important to consider building stronger family units that can provide proper guidance and support to ensure that generations are built on a solid base. Therefore, a holistic, multi-level, multi-sectoral intervention is required for all role players such as government departments, non-governmental organisations, and community and faithbased organisations. Focusing on their scope of practice with a view to contributing towards reduction of harm caused by alcohol should be a priority for all. Civil society and community members need to be involved in efforts to address the alcohol abuse and other related problems. Research to understand particular situations of different areas is needed. On-going evaluation of current policies and intervention strategies should be conducted with a view to determine the impact on targeted problems. The results of research and evaluation would then inform practice and policy development.

There is a need to develop and increase the number of treatment centres and access to affordable and effective treatment and rehabilitation, especially in the public hospitals, which many will be able to use. Restrictions to control alcohol consumption by controlling the availability of alcohol is a responsibility of all role players such as the tribal authority. Families need to be informed about the dangers and how to respond to prevent problems from arising. Control of numbers of drinking or selling outlets, especially unregistered ones, is necessary. Harm reduction includes working with individual drinkers to help them manage their drinking problem with insight. Abstinence should be encouraged to all, but more to those who have not started taking alcohol, especially young people who tend to experiment with alcohol.

For community support networks to manage alcohol and related problems, proper assessment is needed. Interventions should be targeted for specific targeted groups taking into consideration their socio-economic position. Multi-level and multidisciplinary collaboration and interventions should be considered and enhanced at all times. Continuous evaluation of policies and intervention strategies is critical to ensure that a dynamic situation is given attention and the challenges are addressed. Ms B Bathabile, Minister of Social Development, in the preamble of the NDMP, 2013-2017 
emphasises the point that "the magnitude of the alcohol and drug problem requires collective national action across all spheres. This sense of unity must be characterised by a coordinated and an integrated approach that drives us towards a drug-free society".

\section{REFERENCES}

BERKMAN, L.F. \& KAWACHI, I. 2000. Social epidemiology. New York: Oxford University Press.

COUCH, S., FELSTEHAUSEN, G. \& HALLMAN, P. 1997. Skills for life. New York: West Publishing.

EBERSÖHN, L. \& ELOFF, I. 2006. Life skills and Assets ( $2^{\text {nd }}$ ed). Pretoria: Van Schaik Academic.

FREEMAN, J. (undated). Services Seta Employee Assistance Programme Toolkit: Addiction - managing substance abuse in the workplace.

HOCHFELD, T. 2007. Missed opportunities: conservative discourses in the draft National Family Policy of South Africa. International Social Work, 50(1):79-91.

LYNCH, J. \& KAPLAN, G. 2000. Socio-economic position. In: BERKMAN, L.F. \& KAWACHI, I. 2000. Social epidemiology. New York: Oxford University Press, 13-35.

MAIL \& GUARDIANONLINE. 2009. Shebeen owners protest W Cape liquor Act. Cape Town, South Africa, 27 January.

MARTINIC, M. 2006. Patterns of drinking and the need for targeted interventions. In: Conference Report - BUNING, E. (ed). Paper presented at the $3^{\text {rd }}$ International Conference on Alcohol and harm reduction - Creating realistic and concrete solutions, 22 - 25 October 2006, Cape Town: South Africa. 1-73.

McLEOD, S. 2010. Behavioral therapy. [Online] Available: http://www.simply psychology.org/behavioral-therapy.html.

MEDINA-MORA, M.E. 2005. Prevention of substance abuse: a brief overview. World Psychiatry, 4(1):25-30.

MEEL, B.L. 2006. Alcohol-related traumatic deaths in Transkei, South Africa. Internet Journal of Medical Update, 1(1):Jan-June.

MKHIZE, B. 2006. Need for ambassadors, champions and role models to tell the message. In: Conference Report - BUNING, E. (ed). Paper presented at the $3^{\text {rd }}$ International Conference on Alcohol and harm reduction - Creating realistic and concrete solutions, 22-25 October 2006, Cape Town: South Africa, 1-73.

MOKDAD, A.H., BREWER, R.D. \& WARNER, L. 2007. Binge drinking is a problem that cannot be ignored. Preventive Medicine, 44:303-304.

MONTEIRO, M. 2001. A World Health Organization perspective on alcohol and illicit drug use and health. European Addiction Research, 7(3):98-103.

MOROJELE, N.K., PARRY, C.D.H. \& BROOK, J.S. 2009. Substance abuse and the young. Medical Research Council Brief. 
NQAKULA, C. 2006. Crime prevention and combating (monitoring and evaluation media briefing). [Online] Available: www.info.gov.za/speeches/2006/060928 10451001.htm. [Accessed: 20/07/2009].

NZIMAKWE, T.I. 2008. Addressing unemployment and poverty through public works programmes in South Africa. International NGO Journal, 3(12):207-212.

PARRY, C.D.H. 2000. Alcohol problem in developing counties: challenges for the new millennium. Alcohol in developing countries. Suchtmed, 2(4):216-220.

PARRY, C.D.H. 1998. Substance abuse in South Africa: country report focusing on young persons. WHO/UNDCP Regional Consultation, 24-26 February, Zimbabwe.

PARRY, C. \& BENNETS, A. 1998. Alcohol Policy and Public Health in South Africa. United Kingdom: Oxford University Press.

PRIDEMORE, W.A. 2006. Weekend effects on binge drinking and homicide: the connection between alcohol and violence in Russia. Addiction, 99(8):1034-1041.

RATAEMANE, S. 2004. Central Drug Authority Report. [Online] Available: www.dsd.gov.za/docs_guidelines/2005/docs/cda2004.doc.

RATAEMANE, S. \& RATAEMANE, L. 2006. Alcohol consumption in South Africa. International Journal of Drug Policy, 17:373-375.

ROBSON, G. \& MARLATT, G.A. 2006. Harm reduction and alcohol policy. International Journal of Drug Policy, 255-257.

SOUTH AFRICA. LIQUOR ACT, No 59 of 2003. Gazette No 26294. Cape Town: Government Gazette.

SOUTH AFRICA. 2006-2011. National Drug Master Plan 2006 - 2011. [Online] Available: www.welfare.gov.za/Documents/2007.

SOUTH AFRICA. 2013-2017. National Drug Master Plan 2013-2017. [Online] Available: www.dsd.gov.za.

SOUTH AFRICA. 2008. Prevention of and Treatment of Substance Abuse Act No 70 of 2008. Gazette No 32150 Cape Town: Government Gazette.

SOUTH AFRICA. 2008. Western Cape Liquor Act No 4 of 2008. 6582 - 27 November 2008. Cape Town: Provincial Gazette Extraordinary.

SOUTH AFRICA. 1997. White Paper for Developmental Social Welfare, February 1997.

SOUTH AFRICA. 2009. Sunday Times newspaper, 19 July 2009.

STIMSON, G. 2006. Reducing alcohol related harm- what are the options and what can we do. In: Conference Report - BUNING, E. (ed). Paper presented at the $3^{\text {rd }}$ International Conference on Alcohol and harm reduction - Creating realistic and concrete solutions, 22-25 October 2006, Cape Town: South Africa, 1-73. 
WELCH, G.J. 1987. An integrated approach to social work practice. In: McKENDRINK, B. (ed) Introduction to Social Work in South Africa. Pinetown: Owen Burgess Publishers, 152-176.

WOMEN'S RURAL ADVOCACY PROGRAMS. 2007. Alcohol abuse and domestic violence. [Online] Available: www.letwrap.com/dvinfo/alcohol.htm.

WORLD HEALTH ORGANISATION. 2004. Global Status Report on Alcohol Abuse. Geneva.

WORLD HEALTH ORGANISATION - AFRICA. 2008. Actions to reduce the harmful use of alcohol. Regional Committee for Africa.

WORLD HEALTH ORGANISATION - EUROPE. 2005. Policy Briefing - Alcohol and Interpersonal violence.

WORLD HEALTH ORGANISATION. 2014. Global Status Report on Alcohol Abuse and Health. Geneva.

ZAWAIRA, F. 2009. The burden of alcohol consumption in the African Region. World Health Organization.

Dr Marilyn Setlalentoa, School of Social Sciences, North-West University, Mafikeng Campus; Prof Elma Ryke, Prof Herman Strydom, School of Psychosocial Behavioural Sciences (Social Work) Potchefstroom Campus, South Africa. 